Review article

\title{
Efficacy of supplementation of probiotics on maternal glycaemic control - A systematic review and meta-analysis of randomized controlled trials
}

\author{
Kavitha Ramanathan, PhD Scholar ${ }^{\text {a, *, Nalini Sirala Jagadeesh, Principal }}{ }^{\text {a }, ~ U s h a ~ V i s h w a n a t h, ~}$ \\ Head $^{\mathrm{b}}$, Celina Dayal, Vice-Principal ${ }^{\mathrm{c}}$, Ramesh Chandrababu, Lecturer ${ }^{\mathrm{d}}$, Mark Hayter, \\ Professor ${ }^{\mathrm{e}}$ \\ ${ }^{\text {a }}$ Faculty of Nursing, Sri Ramachandra University of Higher Education \& Research, Porur, Chennai, Tamil Nadu, India \\ ${ }^{\mathrm{b}}$ Department of Obstetrics \& Gynaecology, Sri Ramachandra University of Higher Education \& Research, Porur, Chennai, Tamil Nadu, India \\ c Omayal Achi College of Nursing, Puzhal, Chennai, India \\ ${ }^{\mathrm{d}}$ Manipal College of Nursing, Manipal Academy of Higher Education, Manipal, Karnataka, 576104, India \\ ${ }^{\text {e }}$ Faculty of Health Sciences, Department of Nursing, University of Hull, Cottingham Road, Hull, HU6 7RX, United Kingdom
}

\section{A R T I C L E I N F O}

\section{Keywords:}

Probiotics

Supplementation

GDM

Lactobacillus

Fasting blood glucose

Glycaemic control biomarkers

Meta-analysis

Randomized clinical trials

Systematic review

\begin{abstract}
A B S T R A C T
Aim: To evaluate the evidence pertaining to the efficacy of the supplementation of probiotics on the blood glucose level of pregnant women with gestational diabetes mellitus (GDM).

Background: Women with the GDM are subsequently at risk to develop type 2 diabetes mellitus, within three to six years after delivery. This makes it crucial for all pregnant women with the GDM, to monitor their blood glucose levels regularly to minimize the adverse pregnancy outcomes. The earlier studies revealed that the probiotics could improve glycaemic control and mitigate the adverse effects of type 2 diabetes mellitus.

Design: A systematic review and meta-analysis.

Data sources: The Google Scholar, Pubmed/Medline, Cochrane library, ProQuest, Ovid, and EMBASE were systematically searched for the available clinical trials.

Review methods: Randomized clinical trials (RCTs) for evaluating the effects of the probiotics on the pregnancy outcomes such as glycaemic control as primary outcome were included to achieve the aim of this review and meta-analysis. Two reviewers from the team extracted the data and assessed the risk of bias in the eligible studies independently. The meta-analysis was performed by applying a model of fixed effects using the Revman 5.3 software.

Results: Nine clinical trials involving 1053 participants were included in the meta-analysis. Though the components of probiotics varied significantly, Lactobacillus species was given to all the participants in all the trials included in this review. The results showed that the probiotics asignificantly improved the glycaemic control biomarkers (Fasting blood glucose and insulin sensitivity level) $(\mathrm{P}<0.005)$

Conclusion: Probiotic-supplements seemed to improve the glycaemic control biomarkers. Thus, this review highlights the considerable evidence that the supplementation of probiotics has the beneficial effects on the glycaemic control markers and may be useful as a supplementary therapy among the women with the GDM. This finding would foster the health care professionals and the nurses to create awareness on the potential benefits of the supplementation of the probiotics among the women with the GDM and elevated glycaemic control biomarkers.
\end{abstract}

\section{Introduction}

Pregnancy complicated by diabetes is a common medical condition. It is estimated that the prevalence of diabetes mellitus (DM) during pregnancy ranges from 1 to $14 \%$. It may either be pre-gestational or gestational diabetes mellitus (GDM). The rates are high particularly among the women born in the Asian countries - with some studies showing the prevalence rates of $17 \%{ }^{1}$ According to the World Health Organization, the GDM has been defined as any degree of glucose intolerance occurring - or being discovered - during pregnancy. ${ }^{2}$

\footnotetext{
* Corresponding author.

E-mail address: kavithar@sriramachandra.edu.in (K. Ramanathan).
} 
In addition, there is evidence signifying that both the women with the GDM and their newborn children are at an increased risk of developing diabetes mellitus and metabolic dysfunction later in life. ${ }^{3}$ Furthermore, there are links between the maternal and the neonatal complications that result from the GDM. ${ }^{3}$

There is some evidence suggesting that the use of probiotics could improve the glycaemic control and diminishes some of the adverse effects of type 2 diabetes. ${ }^{4}$ However, how applicable is this to the GDM is unclear. Some studies have reported that the probiotic-supplementation could improve the fasting blood glucose among the GDM women ${ }^{5}$ while others report as the lack of an effect. ${ }^{6}$ This ambiguity led this systematic review and meta-analysis to examine the available data on this issue and, thus, provided an evidence base for the practitioners caring for the pregnant women with the GDM.

\subsection{Background}

Diabetes is the ninth leading cause of death among women globally causing 2.1 million demises per year. Two out of every five women with diabetes are of reproductive age, accounting for over 60 million women worldwide. ${ }^{2}$ Since 1991, the World Diabetes Day has been observed on a theme related to diabetes with an aim to promote the importance of taking coordinated and concerted actions in confronting diabetes as a critical global health issue. The theme for the year 2017 was 'Women and Diabetes: Our Right to a Healthy Future'. The focus of this campaign was to promote the significance of affordable and equitable access for all women at the risk of diabetes or living with diabetes to offer the education on self-management and information they require to better manage their diabetes themselves and improve their health outcomes. ${ }^{30}$

Another vital element of the global response to diabetes is to work for preventing its occurrence. The Prevalence of the GDM has been increasing worldwide especially in the developing countries. In India, the prevalence of the GDM is as high as $20 \%$. Hence, it is crucial to detect women with the GDM as the condition is associated with the diverse range of the maternal and the neonatal outcomes, i.e., the health burden is not only to the mother but also the offspring at a later stage of life. Many clinical trials demonstrate explicitly that the risk for diabetes is programmed in the mother's womb itself. ${ }^{8}$

A recent meta-analysis showed that the women with the gestational diabetes face a greatly increased risk of developing Type 2 diabetes (relative risk 7.43, 95\%, confidence interval 4.79-11.51). ${ }^{5}$ A study from the North India, reported that a large proportion of women with the GDM had some persistent glucose abnormality after birth. The impaired fasting glucose (IFG) was seen in $14.5 \%$ and demonstrated the impaired glucose tolerance (IGT) in $4.8 \%$, while $8 \%$ had both the IFG and the IGT,

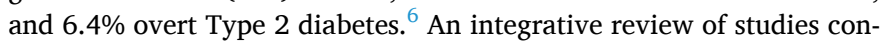
ducted from 2000 to 2013 showed that the programmes for the management of GDM fall into three main types of interventions: (1) dietary and exercise, (2) self-monitoring of blood glucose levels, and (3) counselling/behavioural interventions. The study concluded that the interventions aiming at securing a low glycaemic index diet and increasing levels of activity appeared to be successful at reducing the maternal blood glucose levels and reducing the insulin requirements during pregnancy. The reduction of the maternal blood glucose levels, in turn, is associated with the reduction of macrosomia and gain of maternal weight. $^{9}$

A scoping review of studies on healthcare interventions for the prevention and the control of the GDM in China, reported a wide variety of strategies to address the GDM in China. Almost half of the reviewed studies reported that the interventions that combined different types of interventions had the goal of managing the GDM. Among all the possible combinations of interventions, the dietary + exercise + medication + health education + psychological (DEMHP) interventions accounted for the highest percentage (27.4\%) of these studies. ${ }^{10}$

A systematic review conducted in 2017 to identify the use of probiotics in pregnancy highlighted their impact on the maternal outcomes
- reporting that the use of probiotics in pregnancy could reduce the maternal fasting glucose and the incidence of GDM. The authors argued that the probiotics offered a safe therapeutic tool for the prevention of the complications of pregnancy and the adverse outcomes related to maternal metabolism. The study concluded that further randomised controlled trials were required to determine the potential effects of probiotics in pregnancy particularly among those at the high risk of metabolic disorders, such as overweight and obese pregnant women. ${ }^{11}$

Probiotics offer the possibility of a feasible intervention for improving the metabolic syndromes and preventing the gestational diabetes mellitus. ${ }^{12}$ The Glycaemic control biomarkers such as serum glucose, insulin and glycated haemoglobin were suppressed significantly after the consumption of probiotics, improved the systemic inflammation and oxidative stress markers, and glycaemic control and insulin metabolism. ${ }^{13}$ Probiotics could also prevent the GDM by improving the glucose metabolism and the inflammatory pathways. However, these potential effects cannot be generalised for the prospective treatment of the pregnant women with the GDM. Although some studies showed a link between the probiotics and the improvements in the glycaemic biomarkers such as fasting blood glucose among the mothers with gestational diabetes mellitus, ${ }^{14-19}$ other studies reported no effects on glycaemic biomarkers. ${ }^{20-22} 21$ showed a reduction in both fasting and post-prandial glucose levels in GDM women treated with probiotics, even if the difference was not statistically significant.

This background search reveals the clarity on the importance of a complementary therapy involving the supplementation of probiotics in the maternal glycaemic control worldwide. This led us to conduct this meta-analysis that would provide us a comprehensive awareness on the prospective therapeutic efficiency of the probiotics on the maternal glycaemic biomarkers among the pregnant women with the GDM. ${ }^{23}$

We believe that the results of this meta-analysis would contribute to the possibility of future research on the supplements of probiotics among the pregnant women with the GDM. In consequence, many studies had also recommended for the further randomized controlled trials on the probiotics on the pregnancy outcomes and advised to fully elucidate the potential benefits of the probiotics among the patients with GDM. ${ }^{24-27}$

\section{The review}

\subsection{Aim}

This systematic review and meta-analysis is intended to evaluate the evidence of the efficacy of the supplementation of probiotics on the maternal blood glucose level among the patients with the GDM.

\subsection{Design}

We adopted the guidelines of the reviewer's manual of the Joanna Briggs Institute $(\mathrm{JBI})^{34}$ for the clinical trials to conduct this systematic review and meta-analysis and used the Preferred Reporting Items for the Systematic reviews and Meta-Analyses for Protocols 2015 (PRISMA-P 2015) for reporting this review (PRISMA-P Group et al., 2015). ${ }^{36}$ This review has been presently registered with PROSPERO International prospective register for the systematic reviews (CRD 42018110754).

\subsection{Strategy of search}

A comprehensive strategy of search was developed to identify the relevant studies. Literature sources were identified by using the key terms that were related to PICO (Population or patient, Intervention, comparator/control and outcomes) to develop a strategy of search. The following are the combinations of search terms developed to identify the relevant studies: probiotics\#, Lactobacillus Bifidibacterium, Glycaemic control, Effects, gestational diabetes mellitus, fasting blood glucose level, insulin level. The databases searched for the eligible studies published between 2011 and 2019 by the two authors independently 


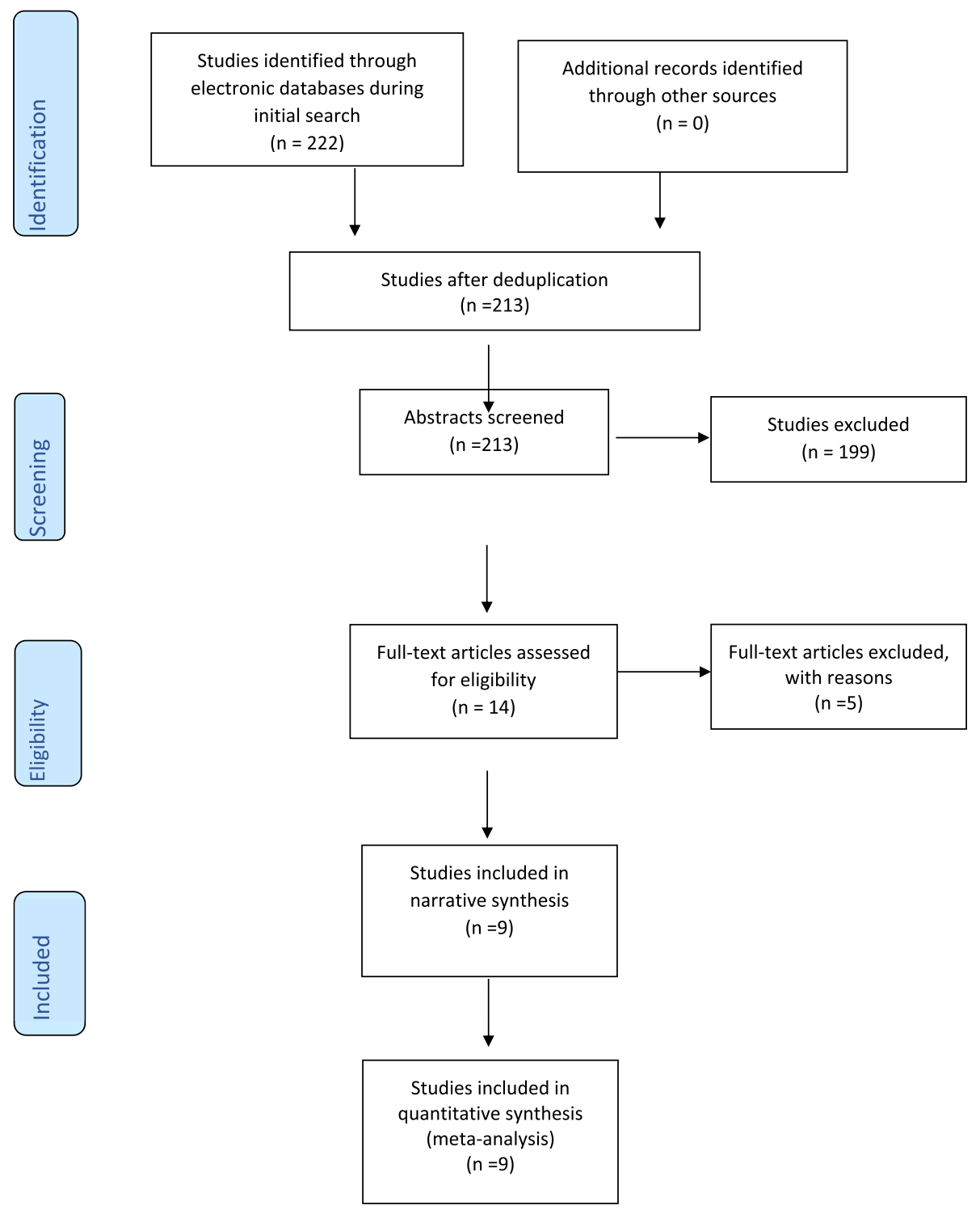

Fig. 1. A flow chart of the process of study selection.

were Pubmed, Cochrane, Proquest and Ovid. The search of references from relevant trials based on the inclusion criteria was done manually. These searches were restricted to the English language and the randomized controlled trials only. An assigned reviewer searched each database, scanned titles, and abstracts for its relevancy, and retrieved the articles that fulfilled the predetermined eligibility criteria and included only those trials that were published in the electronic databases.

Additionally, we also cross referenced for other studies that evaluated the effects of probiotics on the glycaemic control among the women with the GDM. The details of the studies retrieved from each database have been illustrated in the table below.

\subsection{Screening}

The titles of the study were examined for their appropriateness to include into the review, screened and evaluated all the relevant titles identified for the duplicates by using the Reference Manager, and retrieved the abstracts of the chosen titles after deduplication. The two reviewers screened the retrieved abstracts independently by cross checking the pre-established criteria and subsequently, performed a fulltext screening of the relevant abstracts.

\subsubsection{Participants}

The group of randomized controlled trials included the pregnant women with the gestational diabetes mellitus vis a vis the participants who randomly received the supplementation of probiotics as an intervention and placebo in the comparator/control group.

\subsubsection{Intervention}

The randomized clinical trials (RCTs) investigated the effects of the

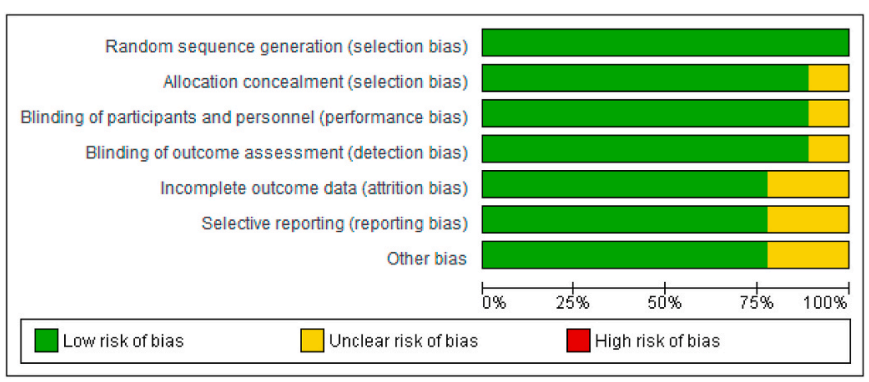

Fig. 2. A graph of risk of bias: A review of the authors' judgements about each item of risk of bias presented as percentages across all the studies included. 
supplementation of the species of probiotics as capsules, or food product with a placebo as a comparator with one or more glycaemic control outcomes.

\subsubsection{Comparison}

The pregnant women with gestational diabetes mellitus in the control group received placebo as a comparator.

\subsubsection{Outcomes}

We analysed the glycaemic control biomarkers, namely fasting blood glucose, as the primary outcomes and used the insulin resistance level as the secondary outcome for this review cum meta-analysis.

\subsubsection{Design of the study}

The studies that focused on the quantitative data but limited to the designs such as Randomized controlled trials (RCTs) that used the probiotics species as a supplementation for the pregnant women with the GDM were included and considered only those that were in the English language.

\subsection{Outcome of the search}

Confining the search to the strategy of search electronic databases only, we identified 35 studies. The initial assessment of the titles enabled us to eliminate the duplicates and further excluded 21 studies performing the deduplication using the software Reference manager. Subsequently, we excluded the additional four studies, as they did not meet the review criteria derived following the PICO. A list of references from the identified articles was reviewed additionally to determine further the appropriate studies, but none was identified. Further, one study was excluded after assessing the full-text because it produced the same results of the outcome measures. Finally, the nine studies were included for the narrative synthesis and meta-analysis. A flow-chart of the study selection-elimination process is represented.

\subsection{Quality appraisal}

Methodological quality of the included trial was assessed by using Cochrane risk of bias tool. The quality assessment was done by the two independent reviewers. This tool rated the quality in six domains such as, random sequence generation, allocation concealment, blinding of participants and personnel, blinding of outcome assessment, incomplete outcome data, and selective reporting. All the trials demonstrated (100\%) a low risk of bias towards the random sequence generation, $90 \%$ of the low risk bias was noted towards allocation concealment, blinding of the participants and the personnel and blinding of the data outcome, while $20 \%$ of unclear risk of bias was witnessed for attrition, reporting and other bias, respectively. The details regarding the percentages across all included trials and judgements about each risk of bias item are presented in Figs. 1 and 2.

\subsection{Extraction of data}

The Joanna Briggs Institute (JBI) data extraction tool for experimental studies from the JBI Reviewer's Manual (Aromataris E, Munn Z, $2017)^{33}$ was used to extract the quantitative data from the included studies. This is a standardized data extraction tool from the JBI- MAStARI. ${ }^{34}$ The data were extracted by one reviewer and checked by the second. This data extraction form comprised the details pertaining to the Author of the trial, year of publication, Journal, Study interventions, populations of the study, methods, study setting, population size, Authors' conclusion, Reviewers' comments, and study results that were significant to the review specific objectives. The two reviewers had to reach a consensus and recreate a table of formal data extraction as per the JBI data extraction tool.

\subsection{Synthesis}

All the trials that measured the Fasting Plasma Glucose (FPG) and the insulin level as the primary outcomes were compared between the trial participants who received probiotics as the supplementation and the participants who were in the control group. Thirty-five studies were identified through the strategy of search using the world builders. This search was limited to the electronic databases without including any other sources for the additional search. This process of study selection is illustrated in Section 2.4 Outcome of the Search.

The meta-analysis was performed with an intention to pool the results of all the RCTs. We estimated the effect sizes of the primary outcomes (continuous outcome) of the supplementation of the probiotics on the FPG and the insulin levels with 95\% confidence intervals pooling the mean differences. The meta-analysis was held for the FPG and the insulin levels as the primary outcome and matched with the control group. We calculated the effects of the supplementation of probiotics by using the model of fixed-effects to compute the weighted mean difference with the confidence interval 95\%. All the data retrieved were analysed and pooled using the software Rev Man 5.3. The guidelines of GRADE approach $^{28,37}$ have been used to give the quality evidence and the strength of outcome measures is reported in Table 2 as 'Summary of findings. The scale of effect had been rated in the following categories: small (effect size around 0.2), medium (effect size around 0.5) and large (effect size of 0.8 or higher) (see Table 3 ).

\section{Results}

\subsection{Characteristics of patients}

The nine clinical trials included for this review cum meta-analysis, involved 1053 participants ranging from 60 to 149 in number in each. All the studies were clinical trials and included pregnant women as the study participants with probiotics as the supplements in the intervention group. All the trials measured the fasting plasma glucose as the primary outcome while the six trials had the insulin sensitivity level as one of the primary outcomes. In all the RCTs, the probiotics were supplemented in the intervention group whereas provided the placebo or conventional food supplement in the control group. The summary of the data of the trials is presented in a tabular form (Table 1).

\subsection{Effects of intervention}

This meta-analysis analysed the FPG and the insulin sensitivity level as the primary outcomes of the intervention. We considered the differences in the primary outcomes as the effect of supplementation of probiotics between the posttest scores of both the probiotics and the placebo groups.

\subsubsection{Effect of the supplementation of probiotics in fasting plasma glucose (FPG)}

The nine RCTs that included 1008 participants revealed the effect of the supplementation of probiotics in pregnant women. ${ }^{14-21,29}$ A significant decrease in the fasting plasma glucose was revealed in the meta-analysis that used the model of fixed effects (MD $=-1.87$, confidence interval $[\mathrm{CI}] 95 \%-2.51,-1.23$ ) and statistically there was a significant difference between the probiotics (intervention) and the control groups $(\mathrm{Z}=5.71, \mathrm{p}<0.00001)$. A moderate quality of evidence is seen as the lesser percentage of unclear risk of bias, considerable heterogeneity and inconsistency as the $\mathrm{I}^{2}$ statistic value is $72 \%$ (Fig. 3 ).

3.2.2. Effect of the supplementation of probiotics on insulin sensitivity level Out of the nine RCTs included for the qualitative synthesis, only six that included 496 participants showed the efficiency of the supplementation of probiotics among pregnant women with the GDM. ${ }^{14-17,19,20}$ A decrease in the insulin sensitivity level was observed 
Table 1

A summary of data and key findings of the studies included.

\begin{tabular}{|c|c|c|c|c|c|c|}
\hline Author \& setting & $\begin{array}{l}\text { Year of } \\
\text { publication }\end{array}$ & $\begin{array}{l}\text { Intervention } \\
\text { (I)/comparator } \\
\text { (C) }\end{array}$ & $\begin{array}{l}\text { Population of the trial \& } \\
\text { size }\end{array}$ & Methods & Study results & Conclusion \\
\hline $\begin{array}{l}\text { Asemi et al. \& (Kashan) } \\
\text { Iran }\end{array}$ & 2013 & $\begin{array}{l}\text { I-Probiotic } \\
\text { yoghurt }(\mathrm{n}= \\
37) \\
\text { C-Conventional } \\
\text { curd }(\mathrm{n}=33)\end{array}$ & $\begin{array}{l}\text { Primigravid } \\
\text { Total- } 70\end{array}$ & RCT & $\begin{array}{l}\text { The consumption of probiotic yogurt } \\
\text { for } 9 \text { weeks did not affect the serum } \\
\text { insulin levels and the HOMA-IR } \\
\text { score, however, significant } \\
\text { differences were found when these } \\
\text { variables were compared between } \\
\text { the probiotics and the conventional } \\
\text { yogurts. }\end{array}$ & $\begin{array}{l}\text { The author concluded that daily } \\
\text { consumption of probiotic yogurt for } \\
9 \text { weeks might help the pregnant } \\
\text { women prevent developing insulin } \\
\text { resistance. }\end{array}$ \\
\hline $\begin{array}{l}\text { Sadegh Jafarnejad et al. } \\
\quad \& \text { ((Sari) Iran }\end{array}$ & 2016 & $\begin{array}{l}\text { I }- \text { probiotic } \\
\text { capsules }(\mathrm{n}= \\
41) \\
\text { C- Placebo }(\mathrm{n}= \\
41)\end{array}$ & $\begin{array}{l}\text { Pregnant women } \\
\text { diagnosed with the } \\
\text { GDM } \\
\text { Total- } 82\end{array}$ & RCT & $\begin{array}{l}\text { Subsequent to } 8 \text { wk of probiotics and } \\
\text { placebo supplementation, the FPG, } \\
\text { the HbA1c, the HOMA-IR, and the } \\
\text { insulin levels remained unchanged } \\
\text { in both the groups. However, there } \\
\text { were significant differences in the } \\
\text { insulin levels and the HOMA-IR. }\end{array}$ & $\begin{array}{l}\text { The study concluded that among } \\
\text { the women with the GDM, the } \\
\text { supplementation of probiotics } \\
\text { (VSL\#3) might help to modulate } \\
\text { some inflammatory markers and } \\
\text { might have beneficial effects on the } \\
\text { glycaemic control. }\end{array}$ \\
\hline $\begin{array}{l}\text { Karamali M et al., } \\
\text { Tehran, Iran }\end{array}$ & 2016 & $\begin{array}{l}\text { I- Probiotic } \\
\text { capsules }(\mathrm{n}= \\
30 \\
\text { C- Placebo }(\mathrm{n}= \\
\text { 30) }\end{array}$ & $\begin{array}{l}\text { Primigravida, aged } \\
18-40 \text { years } \\
\text { Total }-60\end{array}$ & RCT & $\begin{array}{l}\text { After the 6-week intervention, the } \\
\text { group with the supplementation of } \\
\text { probiotics showed a significant } \\
\text { decrease in the fasting plasma } \\
\text { glucose, the serum insulin levels, } \\
\text { and a significant increase in the } \\
\text { quantitative index of the insulin } \\
\text { sensitivity check. }\end{array}$ & $\begin{array}{l}\text { Overall, the study results have } \\
\text { demonstrated that supplementing } \\
\text { with probiotics among patients } \\
\text { with the GDM had beneficial effects } \\
\text { on glycaemic control. }\end{array}$ \\
\hline $\begin{array}{l}\text { Lindsay KL, Brennan L, } \\
\text { Kennelly MA et al. } \\
\text { Ireland } \\
\text { (ISRCTN97241163 } \\
\text { Part B). }\end{array}$ & 2015 & $\begin{array}{l}\text { I-Probiotic } \\
\text { capsules } \\
\text { C- Placebo } \\
\text { capsule (n- 75) }\end{array}$ & $\begin{array}{l}\text { Gravid women with } \\
\text { new diagnosis of } \\
\text { gestational diabetes or } \\
\text { impaired glucose } \\
\text { tolerance (total -149) }\end{array}$ & RCT & $\begin{array}{l}\text { There were no differences between } \\
\text { the probiotics and the placebo } \\
\text { groups in the post intervention } \\
\text { fasting glucose levels } \\
\text { But, among } 100 \text { women who } \\
\text { managed with diet and exercise } \\
\text { alone, demonstrated a decrease in } \\
\text { the fasting plasma glucose } \\
\text { significantly within both the } \\
\text { probiotics and the placebo groups, } \\
\text { but the levels between the groups } \\
\text { did not differ significantly. }\end{array}$ & $\begin{array}{l}\text { A probiotic capsule intervention } \\
\text { among women with the abnormal } \\
\text { glucose tolerance had no impact on } \\
\text { the glycemic control. }\end{array}$ \\
\hline $\begin{array}{l}\text { Wicken KL et al. } \\
\text { Auckland, New } \\
\text { Zealand }\end{array}$ & 2017 & $\begin{array}{l}\text { I-Probiotic } \\
\text { capsule (n - } \\
212 \text { ) } \\
\text { C- placebo (n - } \\
211 \text { ) }\end{array}$ & $\begin{array}{l}\text { Pregnant women (total } \\
=424 \text { ) }\end{array}$ & RCT & $\begin{array}{l}\text { There were lower relative rates (RR) } \\
\text { of GDM (IADPSG definition) in the } \\
\text { probiotics group. The intervention } \\
\text { group was associated with the lower } \\
\text { rates of the GDM among the women } \\
\text { aged } \geq 35 \text { years and among the } \\
\text { women with a history of the GDM in } \\
\text { the previous pregnancy. These rates } \\
\text { did not differ significantly from } \\
\text { those of women without these } \\
\text { characteristics. }\end{array}$ & $\begin{array}{l}\text { The study results revealed that } \\
\text { prevalence of GDM was } \\
\text { significantly lower in the HN001 } \\
\text { group, than in the placebo group. } \\
\text { It concluded that the HN001 } \\
\text { supplementation for } 14-16 \text { weeks' } \\
\text { gestation might reduce prevalence } \\
\text { of GDM among the older women } \\
\text { and those with the previous GDM. }\end{array}$ \\
\hline $\begin{array}{l}\text { Bita Badenoosh et al. } \\
\text { Iran }\end{array}$ & 2017 & $\begin{array}{l}\text { I-Probiotic } \\
\text { capsule }(\mathrm{n}= \\
\text { 30) } \\
\text { C- Placebo }\end{array}$ & $\begin{array}{l}\text { Primigravid women } \\
\text { with GDM }\end{array}$ & RCT & $\begin{array}{l}\text { There was a significant decrease in } \\
\text { the FPG. }\end{array}$ & $\begin{array}{l}\text { Overall, the supplementation of } \\
\text { probiotics among the women with } \\
\text { the GDM for } 6 \text { weeks had beneficial } \\
\text { effects on the FPG. }\end{array}$ \\
\hline $\begin{array}{l}\text { Neda Dolatkah et al. } \\
\text { Turkey }\end{array}$ & 2015 & $\begin{array}{l}\text { I-Probiotic } \\
\text { capsule }(\mathrm{n}= \\
32) \\
\text { C-Placebo }(\mathrm{n}= \\
32)\end{array}$ & $\begin{array}{l}\text { Pregnant women with } \\
\text { GDM }\end{array}$ & RCT & $\begin{array}{l}\text { Fasting blood sugar decreased in } \\
\text { both the interventional and the } \\
\text { control groups, and the decrease in } \\
\text { probiotic group significantly was } \\
\text { higher during the study period. } \\
\text { The index of insulin resistance in the } \\
\text { probiotic group had a reduction over } \\
\text { the study period, however, the } \\
\text { observed reduction was statistically } \\
\text { significant. }\end{array}$ & $\begin{array}{l}\text { The supplementation of probiotics } \\
\text { appeared to effect the glucose } \\
\text { metabolism among the pregnant } \\
\text { women with the GDM. }\end{array}$ \\
\hline $\begin{array}{l}\text { Ebrahim etr. al, Tabriz, } \\
\text { Iran }\end{array}$ & 2019 & $\begin{array}{l}\mathrm{I}=\text { Probiotic } \\
\text { yoghurt }(\mathrm{n}= \\
42) \\
C=\text { Placebo (n } \\
=42)\end{array}$ & $\begin{array}{l}\text { Pregnant women with } \\
\text { GDM }\end{array}$ & RCT & $\begin{array}{l}\text { The FPG and the HbA1C decreased } \\
\text { significantly in the probiotics group. }\end{array}$ & $\begin{array}{l}\text { Overall, the study revealed that the } \\
\text { better control of blood glucose can } \\
\text { be achieved by the consumption of } \\
\text { probiotic yoghurt. }\end{array}$ \\
\hline $\begin{array}{l}\text { Jamilian et al., Arak, } \\
\text { Iran }\end{array}$ & 2016 & $\begin{array}{l}\mathrm{I}=\text { Probiotic } \\
\text { capsule }(\mathrm{n}= \\
30) \\
\mathrm{C}=\text { Placebo } \\
\text { capsule }(\mathrm{n}= \\
30)\end{array}$ & Pregnant women & RCT & $\begin{array}{l}\text { The pregnant women supplemented } \\
\text { with the probiotics demonstrated } \\
\text { reduced serum insulin } \\
\text { concentrations, and increased } \\
\text { sensitivity index. }\end{array}$ & $\begin{array}{l}\text { Overall, the supplementation of } \\
\text { probiotics among the pregnant } \\
\text { women in the first half had } \\
\text { beneficial effects on the markers of } \\
\text { the insulin metabolism. }\end{array}$ \\
\hline
\end{tabular}


Table 2

Efficiency of probiotics compared to placebo for [health problem]

Patient or population: [health problem]

Setting:

Intervention: efficiency of probiotics

Comparison: placebo.

\begin{tabular}{|c|c|c|c|c|c|c|}
\hline \multirow[t]{2}{*}{ Outcomes } & \multicolumn{2}{|c|}{ Anticipated absolute effects* (95\% CI) } & \multirow{2}{*}{$\begin{array}{l}\text { Relative } \\
\text { effect }(95 \% \\
\text { CI) }\end{array}$} & \multirow{2}{*}{$\begin{array}{l}\text { № of } \\
\text { participants } \\
\text { (studies) }\end{array}$} & \multirow{2}{*}{$\begin{array}{l}\text { Certainty of the } \\
\text { evidence } \\
\text { (GRADE) }\end{array}$} & \multirow[t]{2}{*}{ Comments } \\
\hline & Risk with placebo & $\begin{array}{l}\text { Risk with efficiency } \\
\text { of probiotics }\end{array}$ & & & & \\
\hline $\begin{array}{l}\text { Fasting } \\
\text { blood } \\
\text { glucose }\end{array}$ & $\begin{array}{l}\text { The mean fasting } \\
\text { blood glucose ranged } \\
\text { from } 74.3 \text { to } 94 \mathrm{mg} / \\
\text { dl }\end{array}$ & $\begin{array}{l}\text { MD } 1.87 \mathrm{mg} / \mathrm{dl} \\
\text { lower }(2.51 \text { lower } \\
\text { to } 1.23 \text { lower })\end{array}$ & - & 1008 (9 RCTs) & $\begin{array}{l}\bigoplus \bigoplus \bigoplus \bigcirc \\
\text { MODERATE } \\
\text { a b c , d e f g, h } \\
,,,,,,\end{array}$ & $\begin{array}{l}\text { Probiotic supplements show beneficial effects on } \\
\text { glycaemic control by reducing the fasting blood glucose } \\
\text { levels. Moderate effect size. Statistically significant at } \mathrm{p} \\
=0.00001 \text {. SMD of }-1.87 \text { lower represents the } \\
\text { considerable difference between the groups and may be } \\
\text { clinically relevant. }\end{array}$ \\
\hline
\end{tabular}

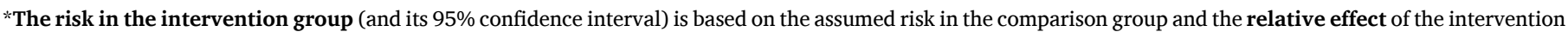

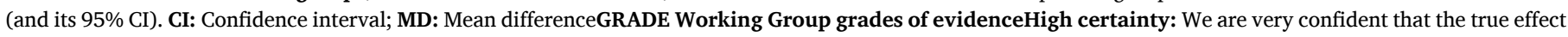

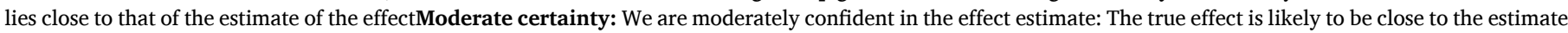

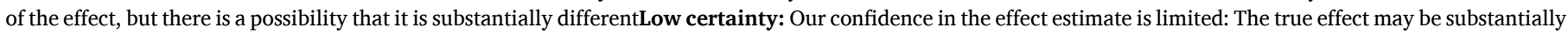

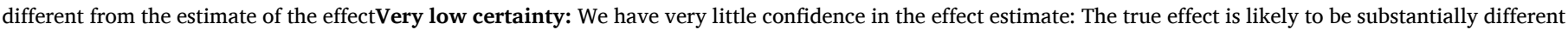
from the estimate of effect.

a Presence of unclear risk of bias made the author to downgrade as serious.

b The majority of the studies is conducted at the same country and the studies recommend for more studies that are vigorous.

c The methodological aspects of a few studies are not clearly stated.

d Presence of moderate effect might positively indicate the beneficial effects.

e Funnel plot shows a few studies are scattered away from the plot indicating the existence of publication bias.

${ }^{f}$ Presence of wider range of effect indicates a considerable effect.

$g$ Existence of considerable effect in the majority of studies indicates a spurious effect on the probiotics intervention.

h All the studies have different dose levels of probiotic species, thus, it is judged as a dose that may have a gradient.

Table 3

Efficiency of the probiotics compared to the placebo for [health problem]

Patient or population: [health problem]

Setting:

Intervention: efficiency of probiotics

Comparison: placebo.

\begin{tabular}{|c|c|c|c|c|c|c|}
\hline \multirow[t]{2}{*}{ Outcomes } & \multicolumn{2}{|c|}{ Anticipated absolute effects* (95\% CI) } & \multirow{2}{*}{$\begin{array}{l}\text { Relative } \\
\text { effect }(95 \% \\
\text { CI) }\end{array}$} & \multirow{2}{*}{$\begin{array}{l}\text { № of } \\
\text { participants } \\
\text { (studies) }\end{array}$} & \multirow{2}{*}{$\begin{array}{l}\text { Certainty of the } \\
\text { evidence (GRADE) }\end{array}$} & \multirow[t]{2}{*}{ Comments } \\
\hline & Risk with placebo & $\begin{array}{l}\text { Risk with } \\
\text { efficiency of } \\
\text { probiotics }\end{array}$ & & & & \\
\hline $\begin{array}{r}\text { Insulin } \\
\text { level }\end{array}$ & $\begin{array}{l}\text { The mean insulin } \\
\text { level ranged from } \\
\mathbf{1 2 . 3}-\mathbf{0 . 5}\end{array}$ & $\begin{array}{l}\text { MD } 0.59 \text { lower } \\
(0.81 \text { lower to } \\
0.37 \text { lower })\end{array}$ & - & 496 (6 RCTs) & 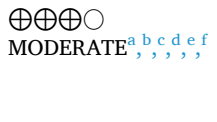 & $\begin{array}{l}\text { Efficiency of probiotics reduces inulin level. Moderate } \\
\text { effect size. Statistically significant at } p=0.00001 \text {. SMD } \\
\text { of }-0.59 \text { lower represents the higher difference between } \\
\text { the groups and may be clinically relevant. }\end{array}$ \\
\hline
\end{tabular}

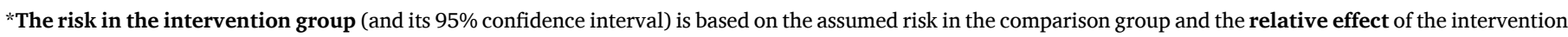
(and its 95\% CI). CI: Confidence interval; MD: Mean difference.

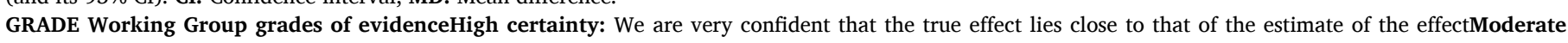

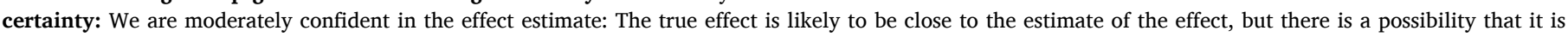

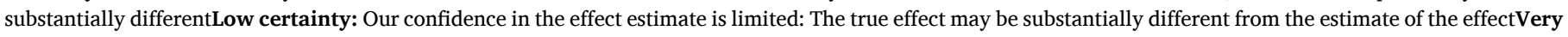
low certainty: We have very little confidence in the effect estimate: The true effect is likely to be substantially different from the estimate of effect.

${ }^{a}$ Due to existence of unclear risk of bias, the risk of bias is judged as serious.

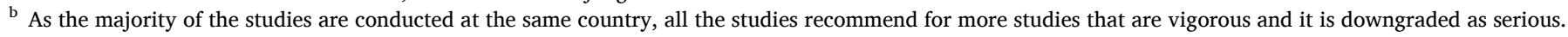

c As the effect size is moderate, it is downgraded as serious.

d Since a few studies have not clearly reported the measured outcomes, it is downgraded as suspected publication bias.

e Since majority of studies have clearly proclaimed that the probiotics might have beneficial effects it suggested for having spurious effect.

${ }^{f}$ All the studies have different dose levels of probiotic species, thus, it is judged as a dose that may have a gradient.

in the meta-analysis that was analysed using the fixed effect sizes (MD = -0.59 , confidence interval [CI] $95 \%-0.81,-0.37$ ) and statistically there was a significant difference between the probiotics and the control groups ( $\mathrm{Z}=5.29, \mathrm{p}<0.00001)$. A low quality of evidence is observed due to considerable heterogeneity, unclear risk of bias and inconsistency as the $\mathrm{I}^{2}$ statistic value is $95 \%$ (Figs. 2 and 4 ).

\subsection{Publication bias}

Since this systematic review and meta-analysis was done with the available minimal trials, the possibility for publication bias was not evaluated.

\subsection{Quality of evidence}

Overall, moderate to low quality of evidences was found for the 


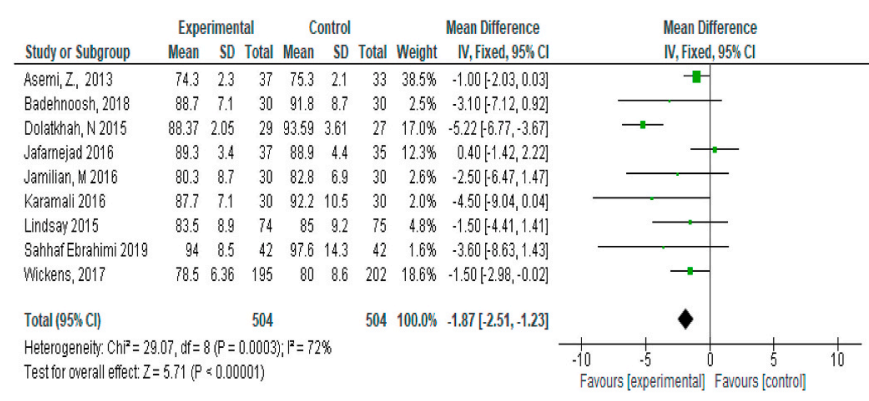

Fig. 3. Effect of the supplementation of probiotics on the fasting plasma glucose.

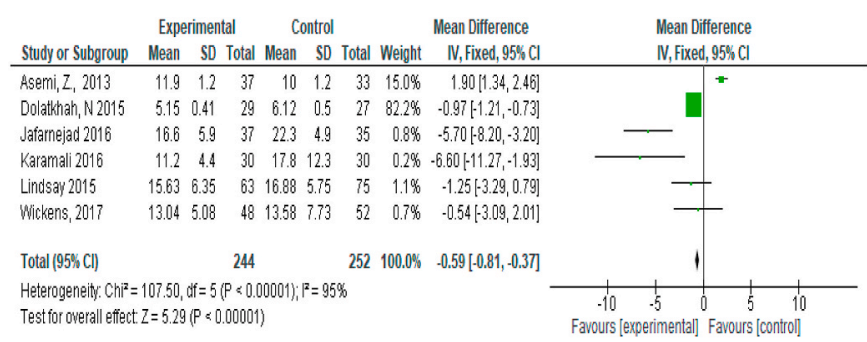

Fig. 4. Effect of the supplementation of probiotics on the insulin levels among the pregnant women with the GDM.

primary outcome fasting plasma glucose and the insulin sensitivity, respectively, due to the lower percentage of unclear risk of bias and considerable substantial heterogeneity of the results.

\section{Discussion}

This review of the randomized controlled trials suggests that there is an evidence that the supplements of probiotics can improve the maternal glycaemic markers and the glycaemic control among the pregnant women. Our review and meta-analysis included the nine studies published between 2011 and 2019 - identified five studies reporting that the supplements of probiotics to pregnant women showed the beneficial effects on the glycaemic control, while the four studies reported no positive result. The most of the studies that we reviewed produced positive results.

In our analysis, we included nine trials and analysed evaluating the beneficial effects of probiotics on the fasting plasma glucose (FPG). Out of the nine, five trials concluded that there was a beneficial effect on the fasting plasma glucose of the glycaemic markers whereas, the four trials demonstrated that although there were changes in the FPG these results were not significant. Out of the nine, two trials highlighted that the supplementation of probiotics in early pregnancy might reduce the prevalence of GDM. However, all the nine trials showed that the supplementation of probiotics either as a capsule or yoghurt significantly reduced the FPG levels - with no adverse effects on the pregnancy (Fig. 3).

We also conducted an analysis to explore the effects of the supplements of probiotics on the serum insulin levels or insulin sensitivity index. This analysis included six trials and out of which two trials showed positive results while the other two trials showed changes in their values between the groups but the difference was not significant. Another two trials showed no positive results. Given that, all six trials were included in the meta-analysis. The meta-analysis showed that the supplements of probiotics improved the index of insulin sensitivity that consequently reduced the serum concentrations of the insulin level. Further, none of the trials included reported adverse effects of the supplements of probiotics upon pregnancy (Fig. 4).
The results of our meta-analysis are congruent with the previous systematic reviews that concluded that the supplementation of probiotics had beneficial effects on the glycaemic markers. ${ }^{14-21,29}$ Our study has explored the benefits of the supplements of probiotics specifically for the pregnant women with the GDM when matched with the previous systematic reviews that evaluated in the general metabolic diseases and conditions.

Our review highlights that there is a considerable evidence that the supplementation of probiotics has beneficial effects on the glycaemic control markers among the pregnant women. This finding would foster the health care professionals and the nurses to develop awareness on the potential benefits of the supplementation of probiotics on the glycaemic control markers.

Thus, the use of the intervention of probiotics might favour the pregnant women with elevated glycaemic control biomarkers. Although, the probiotics alone may not improve the glycaemic status of the pregnant women, the results of this review are considerable and might contribute to the scope of the usage of the supplementation of probiotics among the pregnant women with the GDM. This insists the need for implementing probiotics as the therapeutic supplementation for the pregnant women with the GDM.

\subsection{Limitations}

This review meta-analysis included only the studies published in the English language that could contribute to the language bias. Since the majority of the trials included were conducted in Iran, the reliability of evidence becomes questionable. Other concerns were unpublished researches, small sample size, low quality of evidence due to the existence of unclear risk of bias and the noticeable heterogeneity among the trials included.

\section{Conclusion}

There is evidence that the supplementation of probiotics has the potential to improve the glycaemic control markers among the pregnant women with the GDM. The results of this systematic review and metaanalysis illustrate that the supplementation of probiotics improves the maternal glycaemic control biomarkers among the pregnant women. How this can be translated into clinical practice is a crucial question for the practitioners working with the pregnant women. Although, given the diversified results from the published studies involved in our review and meta-analysis, there is a need for further high quality studies to strengthen the evidence base around the therapeutic use of the probiotics among the pregnant women.

\section{Funding statement}

We the authors had not received any financial aid for conduction of this review, analysis and/or towards reporting of this article.

\section{Declaration of competing interest}

The authors declare no conflict of interest.

\section{References}

1 Begum S, Dey S, Fatema K. Neonatal glycemic status of infants of diabetic mothers in a tertiary care hospital. Indian J Endocr Metab. 2018;22:621. https://doi.org/ 10.4103/ijem.IJEM_689_17.

2 Mathers C, Fat DM, Boerma JT, World Health Organization, eds. The Global Burden of Disease: 2004 Update. Geneva, Switzerland: World Health Organization; 2008.

3 Shah BR, Retnakaran R, Booth GL. Increased risk of cardiovascular disease in young women following gestational diabetes mellitus. Diabetes Care. 2008;31:1668-1669. https://doi.org/10.2337/dc08-0706.

4 Seshiah V, Balaji V, Balaji MS, et al. Prevalence of gestational diabetes mellitus in South India (Tamil Nadu)-a community based study. J Assoc Physicians India. 2008; 56:329-333. 
5 Mobini R, Tremaroli V, Ståhlman M, et al. Metabolic effects of Lactobacillus reuteri DSM 17938 in people with type 2 diabetes: a randomized controlled trial. Diabetes Obes Metab. 2017;19:579-589. https://doi.org/10.1111/dom.12861.

6 Babadi M, Khorshidi A, Aghadavood E, et al. The effects of probiotic supplementation on genetic and metabolic profiles in patients with gestational diabetes mellitus: a randomized, double-blind, placebo-controlled trial. Probiotics \& Antimicro. Prot 2019;11:1227-1235. https://doi.org/10.1007/s12602-018-9490-z.

8 Moreno-Indias I, Cardona F, Tinahones FJ, Queipo-OrtuÃ \pm o MI. Impact of the gut microbiota on the development of obesity and type 2 diabetes mellitus. Front. Microbiol. 2014;5. https://doi.org/10.3389/fmicb.2014.00190.

9 Carolan-Olah MC. Educational and intervention programmes for gestational diabetes mellitus (GDM) management: an integrative review. Collegian. 2016;23:103-114. https://doi.org/10.1016/j.colegn.2015.01.001.

$10 \mathrm{Xu}$ T, He Y, Dainelli L, et al. Healthcare interventions for the prevention and control of gestational diabetes mellitus in China: a scoping review. BMC Pregnancy Childbirth. 2017;17:171. https://doi.org/10.1186/s12884-017-1353-1.

11 Taylor BL, Woodfall GE, Sheedy KE, et al. Effect of probiotics on metabolic outcomes in pregnant women with gestational diabetes: a systematic review and meta-analysis of randomized controlled trials. Nutrients. 2017;9. https://doi.org/10.3390/ nu9050461.

12 Barrett HL, Callaway LK, Nitert MD. Probiotics: a potential role in the prevention of gestational diabetes? Acta Diabetol. 2012;49:1-13. https://doi.org/10.1007/s00592 012-0444-8.

13 Ebrahimi ZS, Nasli-Esfahani E, Nadjarzade A, Mozaffari-Khosravi H. Effect of symbiotic supplementation on glycemic control, lipid profiles and microalbuminuria in patients with non-obese type 2 diabetes: a randomized, double-blind, clinical trial. J Diabetes Metab Disord. 2017;16:23. https://doi.org/10.1186/s40200-017-0304-8.

14 Asemi Z, Samimi M, Tabassi Z, et al. Effect of daily consumption of probiotic yoghurt on insulin resistance in pregnant women: a randomized controlled trial. European Journal of Clinical Nutrition. 2013;67:71-74. https://doi.org/10.1038/ejcn.2012.189.

15 Dolatkhah N, Hajifaraji M, Abbasalizadeh F, Aghamohammadzadeh N, Mehrabi Y, Mesgari Abbasi M. Is there a value for probiotic supplements in gestational diabetes mellitus? A randomized clinical trial. $J$ Health Popul Nutr. 2015;33:25. https://doi. org/10.1186/s41043-015-0034-9.

16 Karamali M, Dadkhah F, Sadrkhanlou M, et al. Effects of probiotic supplementation on glycaemic control and lipid profiles in gestational diabetes: a randomized, doubleblind, placebo-controlled trial. Diabetes \& Metabolism. 2016;42:234-241. https://doi. org/10.1016/j.diabet.2016.04.009.

17 Jafarnejad S, Saremi S, Jafarnejad F, Arab A. Effects of a multispecies probiotic mixture on glycemic control and inflammatory status in women with gestational diabetes: a randomized controlled clinical trial. Journal of Nutrition and Metabolism. 2016;2016:1-8. https://doi.org/10.1155/2016/5190846.

18 Badehnoosh B, Karamali M, Zarrati M, et al. The effects of probiotic supplementation on biomarkers of inflammation, oxidative stress and pregnancy outcomes in gestational diabetes. The Journal of Maternal-Fetal \& Neonatal Medicine. 2018;31: 1128-1136. https://doi.org/10.1080/14767058.2017.1310193.

19 Wickens KL, Barthow CA, Murphy R, et al. Early pregnancy probiotic supplementation with Lactobacillus rhamnosus HN001 may reduce the prevalence of gestational diabetes mellitus: a randomised controlled trial. Br J Nutr. 2017;117: 804-813. https://doi.org/10.1017/S0007114517000289.

20 Lindsay KL, Brennan L, Kennelly MA, et al. Impact of probiotics in women with gestational diabetes mellitus on metabolic health: a randomized controlled trial. American Journal of Obstetrics and Gynecology. 2015;212:496.e1-496.e11. https:// doi.org/10.1016/j.ajog.2015.02.008.

21 Sahhaf Ebrahimi F, Homayouni Rad A, Mosen M, Abbasalizadeh F, Tabrizi A, Khalili L. Effect of L. acidophilus and B. lactis on blood glucose in women with gestational diabetes mellitus: a randomized placebo-controlled trial. Diabetol Metab Syndr. 2019;11:75. https://doi.org/10.1186/s13098-019-0471-5.

22 Ghafouri A, Zarrati M, Shidfar F, Heydari I, Shokouhi Shoormasti R, Eslami O. Effect of synbiotic bread containing lactic acid on glycemic indicators, biomarkers of antioxidant status and inflammation in patients with type 2 diabetes: a randomized controlled trial. Diabetol Metab Syndr. 2019;11:103. https://doi.org/10.1186/ s13098-019-0496-9.

23 Han M-M, Sun J-F, Su X-H, et al. Probiotics improve glucose and lipid metabolism in pregnant women: a meta-analysis. Ann Transl Med. 2019;7:99. https://doi.org/ 10.21037/atm.2019.01.61.

24 Reid G, Jass J, Sebulsky MT, McCormick JK. Potential uses of probiotics in clinical practice. Clinical Microbiology Reviews. 2003;16:658-672. https://doi.org/10.1128/ CMR.16.4.658-672.2003.

25 Nitert MD, Barrett HL, Foxcroft K, et al. SPRING: an RCT study of probiotics in the prevention of gestational diabetes mellitus in overweight and obese women. BMC Pregnancy Childbirth. 2013;13:50. https://doi.org/10.1186/1471-2393-13-50.

26 Hsieh F-C, Lee C-L, Chai C-Y, Chen W-T, Lu Y-C, Wu C-S. Oral administration of Lactobacillus reuteri GMNL-263 improves insulin resistance and ameliorates hepatic steatosis in high fructose-fed rats. Nutr Metab (Lond). 2013;10:35. https://doi.org/ 10.1186/1743-7075-10-35.

27 Majella MG, Naik BN, Mahalakshmy T, Chinnakali P. Comment on the maternal and neonatal outcomes of gestational diabetes. J Family Med Prim Care. 2016;5:190-191. https://doi.org/10.4103/2249-4863.184666.

28 Guyatt GH, Thorlund K, Oxman AD, et al. GRADE guidelines: 13. Preparing summary of findings tables and evidence profiles-continuous outcomes. $J$ Clin Epidemiol. 2013; 66:173-183. https://doi.org/10.1016/j.jclinepi.2012.08.001.

29 Jamilian M, Bahmani F, Vahedpoor Z, et al. Effects of probiotic supplementation on metabolic status in pregnant women: a randomized, double-blind, placebo-controlled trial. Arch Iran Med. 2016;19, 687-682 http://www.aimjournal.ir/Article/1065.

30 Nayak PK, Mitra S, Sahoo JP, Daniel M, Mathew A, Padma A. Feto-maternal outcomes in women with and without gestational diabetes mellitus according to the international association of diabetes and pregnancy study groups (IADPSG) diagnostic criteria. Diabetes \& metabolic syndrome. Clinical Research \& Reviews. 2013;7:206-209. https://doi.org/10.1016/j.dsx.2013.10.017.

33 Aromataris E, Munn Z. Joanna Briggs Institute Reviewer's Manual. The Joanna; 2017.

34 Briggs Institute. Available from https://reviewersmanual.joannabriggs.org/; 2017.

36 Moher D, Shamseer L, Clarke M, et al, PRISMA-P Group. Preferred reporting items for systematic review and meta-analysis protocols (PRISMA-P) 2015 statement. Syst Rev. 2015;4:1. https://doi.org/10.1186/2046-4053-4-1.

37 GRADEpro GDT. GRADEpro Guideline Development Tool [Software]. McMaster University; 2015 (developed by Evidence Prime, Inc.). Available from gradepro.org. 